\title{
A COMPETITIVIDADE DE PORTUGAL NA EDUCAÇÃO E NA CIÊNCIA
}

\author{
Sebastião J. Formosinho*
}

\section{A SOCIEDADE EM MUDANÇA}

Encontramo-nos hoje numa sociedade profundamente transformada, em que a velocidade de mudança é cada vez maior. O mundo está atravessado por correntes de ideias e aspirações que se trespassam, misturam e fecundam. Três ou quatro indicadores bastam para ilustrar esta asserção: 18 milhões de desempregados na União Europeia, 1,3 milhões de casos declarados de SIDA através do mundo, 50 milhões de utilizadores da Internet, o equivalente a 2000 milhões de dólares são negociados em títulos, diariamente, a nível mundial.

A mobilidade, a informação, a tecnologia, o carácter não-linear das relações sociais e políticas não são fenómenos de hoje. O que é verdadeiramente novo é a sua intensidade, gerada pelo denso e fértil campo de relações cruzadas de ideias, sistemas e fenómenos, a todos os níveis da vida humana e das suas construções materiais e intelectuais. Por isso vivemos presentemente o fenómeno da globalidade na economia, na circulação da informação, na produção industrial, etc..

A globalidade da economia é um fenómeno complexo que se caracteriza pelo carácter transnacional dos diferentes mercados e sectores produtivos e por uma interacção à escala mundial dos actores económicos, mormente das empresas. A globalização da economia não foi um processo repentino. Houve uma primeira fase na década dos anos 50 e 60 de um forte crescimento do comércio internacional. A segunda fase refere-se ao mercado de capitais; e a terceira, na qual nos encontramos, inicia-se nos anos 80 , com fortes investimentos de carácter interna-

* Escola Superior de Ciências e Tecnologia do Centro Regional das Beiras, Universidade Católica Portuguesa. 
cional e, de modo bem correlacionado, com a internacionalização da tecnologia. Aliás a globalização da economia está profundamente ligada ao crescimento tecnológico, pois uma e outra foram-se mutuamente autocatalisando.

O mundo viu cair um dos seus últimos bastiões da linearidade dos sistemas políticos com o desmantelamento do Império Soviético em 1989. A partir desta data, nas múltiplas vertentes que vão da política à actividade científica, as sociedades evoluídas deixaram de estar moldadas aos padrões do pós-guerra de um mundo bipolar. Quebrada a bipolaridade política do mundo, as características da sua não-linearidade sobressaem. $\mathrm{E}$ as consequências de uma tal não-linearidade são, essencialmente, a capacidade de certas pequenas acções de países, empresas ou indivíduos produzirem grandes efeitos em prazos relativamente curtos; sempre mais longos, é certo, que os produzidos por actuações de grandes potências, monopólios, grupos científicos. Com isto diminui o nosso horizonte de previsibilidade. E com a perda da capacidade de previsão vem a perda de coesão. A ignorância e a incerteza nunca geram solidariedade! .

Se, há poucas dezenas de anos, a visão comum da não-linearidade quase se resumia ao tempo meteorológico ou a algum raro acontecimento político ou social, como o atentado ao Arquiduque Francisco Ferdinando em Sarajevo em 28 de Junho de 1914 ou o Maio de 68 em Paris, hoje sentimos os seus efeitos em áreas muito vastas, das telecomunicações aos materiais, das honestas transacções comerciais às especulações financeiras. Quanto mais necessitamos de uma visão holística, num mundo do não-linear, mais temos de prestar atenção aos pormenores que podem causar grandes efeitos, não amanhã mas passado poucos meses ou anos. Tudo parece possível. As ideias, tal como os capitais, circulam veloz e ferozmente no nosso planeta.

Eis alguns factos que ilustram esta nova problemática. O México entrou na bancarrota em três dias, não por ter deixado de produzir ou por via de alguma revolução política ou social, mas por efeitos especulativos da retirada de capitais, cujas consequências se fizeram sentir, de forma quase instantânea, graças à informática e às telecomunicações.

Hoje, a nível mundial, o volume das operações de actividade real (importação/ exportação) é cerca de 50 vezes inferior ao do movimento monetário, cambiário e de bolsa. Os lucros de muitas multinacionais devem-se mais a estas operações de engenharia financeira do que a actividades produtivas de bens e serviços. Mas sem esta, aquela volatilizava-se.

O custo do operário/hora na Alemanha é cerca de 50 vezes superior ao do Sudeste Asiático. Durante quase meio século um tal diferencial de custo era compensado pelo diferencial de produtividade garantido pela tecnologia instalada na Alemanha. Presentemente há uma mobilidade estratégica das empresas e dos seus meios de produção que, associada à mobilidade dos meios financeiros e à baixa 
dos custos de transportes, permite a deslocalização industrial na busca de custos salariais e encargos sociais mais baixos.

Cada vez mais o tempo é dinheiro. Dados recolhidos numa empresa tecnologicamente mais avançada revelaram que um aumento de $50 \%$ em I\&D reduz a margem de lucro em $3,5 \%$; um acréscimo de $9 \%$ nos custos de produção reduz os lucros em 22\%; a entrada de um produto no mercado com um atraso de 6 meses cifra-se numa baixa de $33 \%$ nos lucros ${ }^{2}$.

Em suma, caminhamos numa sociedade onde a economia assenta cada vez mais no conhecimento profissional: elevadas destrezas e capacidades, alta tecnologia, salários elevados. Novos padrões de trabalho melhor ajustados à mudança e à imprevisibilidade; maior flexibilidade e adaptabilidade, melhores conhecimentos básicos e formação permanente, destrezas menos especializadas, mais elevada capacidade de inovação e reciclagem, maior responsabilidade individual de cada trabalhador, de colarinho azul ou branco.

Cresce o desemprego e a exclusão social. A população europeia está a envelhecer. Os valores tradicionais assentes no papel da família estável estão em declínio. Surge a revolução dos multimedia, o consumismo e a rápida obsolescência de bens e serviços. Mas os saberes científico e técnico possuem um carácter cumulativo que permite um crescimento ilimitado do capital a nível mundial, em contraste com os bens físicos que se tornam obsoletos em prazos relativamente curtos.

\section{O PAPEL DA EDUCAÇÃO}

O sucesso ou o fracasso dos diferentes países no primeiro quartel do próximo século continuará a depender do factor crescimento. E este está ainda intimamente associado às forças e às fraquezas das diferentes indústrias produtivas de cada país. Mas também está ligado à eficiência das "indústrias de serviços", como a banca, o turismo, os serviços de saúde, a educação, etc., porque cada vez mais o valor da coisa produzida assenta na sua parte imaterial, isto é, o seu valor acrescentado é mais fruto da concepção do que da execução. Eis, pois, onde se está a jogar a competitividade das nações.

A organização das sociedades pode ser avaliada em termos de três indicadores: i) proporção do PNB que é estatal, o que vai dar uma medida da extensão em que o Estado assume a responsabilidade dos encargos sociais; ii) o nível de poupança, que é uma medida da disponibilidade de fundos para o investimento; iii) a proporção dos jovens que se encontram no ensino superior, como medida da opção da sociedade em investir no desenvolvimento dos seus recursos humanos. 
A fracção da despesa pública na América do Norte e nos países do Sudeste Asiático é bastante inferior à da Europa, o que mostra que a União Europeia ocupa uma posição ímpar na extensão em que os sistemas de educação, saúde e segurança social são custeados pelo Estado (cerca de $60 \%$ da despesa pública). Por exemplo, a Grã-Bretanha vê 80\% dos encargos de saúde cobertos pelo Estado, enquanto nos Estados Unidos essa fracção é somente de 40\%. É uma área em que os Estados têm grandes dificuldades em controlar os custos a diferentes níveis, devido a evoluções demográficas e progressos tecnológicos nos meios de diagnóstico, em que o acréscimo de qualidade importa em crescimentos quase exponenciais de custos, e ainda devido a excessivos encargos administrativos. Será uma área crítica para a competitividade das nações, cujos custos não poderão baixar de forma significativa sem uma mudança de "estilo de vida" das populações: hábitos alimentares mais saudáveis, diminuição do consumo de tabaco, exercício físico regular.

No que concerne à poupança destaca-se o Japão com níveis de 33\% do PNB (1985-89); a Europa tem níveis entre os 17\% (Grã-Bretanha) e os $24 \%$ (Alemanha), contra uns 16,5\% dos Estados Unidos. Mas, de uma forma geral, independentemente do regime político que vai desde a democracia à ditadura, incluindo até um regime colonial em Hong-Kong, os países do Sudeste Asiático estão organizados da mesma forma: intervenção pública modesta para as questões sociais, elevada poupança e grande esforço na educação. $O$ que mostra que os países vão aprendendo uns com os outros nas suas formas de governação.

A educação é, de uma forma geral, uma prioridade elevada de todos os países desenvolvidos, mas neste domínio interessa muito mais a qualidade do que a quantidade. $O$ investimento na educação apresenta eficiências muito diferenciadas entre os diversos países. Sem dúvida que neste campo pesam diferenças culturais, atitudes de dedicação ao estudo e de motivação dos jovens e outros factores ainda pouco esclarecidos. Eis o objecto deste nosso trabalho que será dissecado na secção seguinte.

Porém, antes de prosseguirmos, convém atentar em que os velhos pilares da riqueza das nações - território, capital e recursos naturais - desempenham um papel cada vez menos relevante. A capacidade de produção agrícola já não é determinada pela área disponível em cada país, pois as nações industrializadas já produzem mais produtos agrícolas do que necessitam. O capital de um país já não se constitui, por si só, em factor determinante do progresso desse mesmo país, porque os mercados internacionais possuem capitais disponíveis e a baixos custos. Os recursos naturais só têm tido papel de relevo num pequeno número de países, como os do Médio Oriente.

Começa a ser motor de crescimento, quer na área produtiva quer dos serviços, um conjunto de factores qualitativos mais ligados à formação educativa e às capacidades e destrezas dos recursos humanos e da organização social: qualidade, 
organização, motivação e auto-disciplina das populações. Vão assumir papel de maior relevo a criatividade individual e a responsabilidade de grupo.

Alguns economistas têm vindo a proporcionar uma visão sobre o efeito quantitativo da educação e do progresso tecnológico no desenvolvimento económico das sociedades e, presentemente, estimam em $80 \%$ este contributo ${ }^{3}$, quando nos finais da década de 70 era tão-somente de $40 \%$. Daí o interesse e a premência das avaliações dos sistemas educativos, mormente da sua componente superior, a universitária. Avaliação que vai percorrendo as instituições europeias, especialmente a partir do início da década de 90 , como reflexo do facto de as sociedades estarem cada vez mais conscientes da importância das instituições educativas no desenvolvimento social e económico das nações e das regiões. Por isso a sociedade deseja avaliar o desempenho destas instituições, em especial das universidades, em face dos objectivos que prosseguem e dos custos que fazem pender sobre o erário público.

\section{COMPETITIVIDADE NA EDUCAÇÃO BÁSICA E SECUNDÁRIA}

A nível do ensino básico, foram publicadas ${ }^{4}$ recentemente algumas das conclusões mais relevantes do Third International Maths and Science Study. Dada a objectividade e universalidade da matemática e das ciências exactas e naturais, estudos de desempenho dos sistemas educativos de diferentes países podem ser realizados simultaneamente, permitindo comparações mais fáceis do que noutras matérias. Recorrem-se a questões tão básicas como:

i) numa sala com 28 estudantes a proporção entre rapazes e raparigas é de 4:3; quantas raparigas há na sala?

ii) para qual dos seguintes produtos é necessário recorrer a bactérias no processo de fabrico: óleo, creme de barbear, sabonete, iogurte?

Numa primeira fase foram inquiridos cerca de 500000 estudantes, com 13 anos de idade, em 41 países. Os resultados do mais alargado estudo educativo internacional encontram-se apresentados na Tabela I. Destacam-se os países do Sudeste Asiático e da Europa de Leste. Singapura surge em primeiro lugar nos dois domínios e a Coreia do Sul, o Japão e a República Checa encontram-se nos seis primeiros lugares em qualquer dos dois domínios. Seis dos "top-15" lugares, quer em matemática quer em ciências, vão para países do Leste Europeu, muito melhor que os países mais ricos da Europa Ocidental. Se a educação tem o peso que referimos no desenvolvimento e na competitividade das nações, por uma questão de sobrevivência como potência económica a União Europeia terá de vir a incluir, a muito curto prazo, países do leste europeu como a República Checa e a Hungria. 
A China, que não figura neste estudo, classificava-se em $1.0^{\circ}$ lugar em matemática no estudo de 1991 e em $14 .^{\circ}$ em ciências; nesse estudo Portugal, entre os vinte países avaliados, obtinha classificações muito modestas, a de $17 .^{\circ} \mathrm{em}$ matemática e $16 .^{\circ}$ em ciências 5 .

Regressando ao estudo de 1996, realce-se que os Estados Unidos se situam no $28 .^{\circ}$ lugar em matemática e $17 .^{\circ}$ em ciências. França e a Alemanha, apesar de acima da média internacional de 500 pontos, têm um mau desempenho, dado o papel de grande relevo que usufruem na União Europeia. Portugal, entre outros, encontra-se abaixo da média nos dois domínios: $37 .^{\circ} \mathrm{em}$ matemática e 33..$^{\circ}$ em ciências. Os dados mostram que o desempenho dos estudantes não está relacionado com o investimento (figura 1), nem com o tamanho das turmas, nem com a formação dos professores. As turmas dos países do Sudeste Asiático são duplas das americanas, inglesas ou francesas. Os Estados Unidos despendem três vezes mais por aluno do que a Coreia do Sul e, no entanto, o desempenho dos seus estudantes é muito inferior.

Nos estudos de 1991 o factor mais relevante parecia ser o do número de horas dedicado ao estudo destas matérias. Os estudos têm vindo a corrigir pontos de crítica, tais como o não avaliarem a criatividade ou o não levarem em conta os critérios de reprovação de cada país. Os novos estudos procuraram corrigir este tipo de criticismos e agora não se verifica correlação tão significativa entre a pontuação de cada país e o número de horas de estudo, como se ilustra (figura 2). Não obstante, na relação entre pontuação e horas lectivas, infelizmente o nosso país é um dos de mais baixa eficiência. Estes resultados internacionais objectivam muitos dos alertas que os meios da indústria ocidental têm lançado aos respectivos governos, sobre a má qualidade do ensino básico e secundário.

Claro que estudos desta índole suscitaram a hostilidade de professores e até de políticos, um pouco por todo o mundo. Presentemente as sociedades e os governos vão ganhando a consciência da sua importância, até porque tais estudos vão produzindo consistentemente uma hierarquização de países ou regiões que parece ser independente do tipo de melhoramentos que têm sido introduzidos nos testes.

Também a nível interno do nosso país há diferenças de índole regional. Os resultados que vamos apresentar correspondem a alunos que concluíram o ensino secundário. A Tabela II apresenta resultados das classificações das Provas Específicas de Química, de carácter nacional, nos anos de 1993 e 1994, em função das localidades onde foram realizadas as provas. Uma característica destes resultados é que correspondem à avaliação por um único centro corrector, de carácter nacional. Destaca-se Macau com um desempenho característico dos países do Sudeste Asiático. No território metropolitano e nas ilhas surgem em primeiro lugar os grandes centros urbanos e de maior tradição universitária (Lis- 
boa, Porto, Coimbra). Acima da média surge um segundo grupo de localidades do litoral, Aveiro e Algarve. Um pouco abaixo da média nacional figuram as cidades de Viseu, Leiria e Setúbal, sendo de realçar o bom desempenho de Viseu como cidade do interior. Em último lugar situa-se os Açores, sendo um pouco surpreendente o baixo desempenho de Évora.

Merece destaque o facto de Macau funcionar nestes resultados como uma "sonda" do sistema educativo oriental em provas nacionais. Tais dados apontariam para uma influência, de certo modo significativa, do tipo de cultura asiática no desempenho educativo. Trata-se de culturas que conciliam bastante bem as tradições e os valores familiares e sociais com as maneiras, os costumes e as exigências modernas das sociedades capitalistas desenvolvidas.

Mas outros resultados parecem não apontar no sentido da influência cultural. Por que razão os estudantes ingleses, que apresentam um tão baixo desempenho em matemática, se aproximam dos resultados asiáticos em ciências? As comparações internacionais estão a permitir confrontar países de diferentes culturas mas com desempenho semelhantes, na busca de factores comuns no ensino destas matérias. Por exemplo, comparações entre o ensino da matemática ministrado no Japão $\left(3 .^{\circ}\right)$ e na Suíça $\left(8 .^{\circ}\right)$, que tem tido uma boa prestação em todos os estudos, revelam que há um conjunto de factores comuns:

i) os alunos do ensino básico despendem muito mais tempo com a aritmética básica do que noutros tópicos de matemática;

ii) os alunos são treinados primeiramente em cálculo mental, da adição, e só depois passam a executar os cálculos no papel; não é permitido o recurso a calculadoras;

iii) os manuais escolares só são oficializados e publicados após um regime experimental exaustivo em diferentes escolas;

iv) são utilizados métodos de ensino interactivo com carácter global, sendo a interacção do professor extensível a toda a turma; os alunos não trabalham em pequenos grupos, saltitando o professor de grupo para grupo;

v) ao longo do ano, os professores fazem grandes esforços para não deixar alunos para trás; aos que se vão atrasando é ministrado ensino suplementar.

Mas as estradas do ensino e da aprendizagem não são um caminho de sentido único. Enquanto os países ocidentais almejam superar os desempenhos do Japão e da Coreia, os países asiáticos buscam para os seus estudantes a criatividade e o individualismo que associam à educação dos países ocidentais. 


\section{COMPETITIVIDADE NA CIÊNCIA}

O valor social dos novos saberes, gerados mediante a investigação científica, assenta na capacidade de inovação que traz ao homem e à sociedade, e que permite preparar o futuro. Tem sido esta uma das lições da História da Humanidade.

Uma avaliação da actividade científica no nosso país, como expressão mais elevada de um sistema educativo visto na sua globalidade e dinamismo de uma auto-formação contínua, tem de ter em conta os seus diferentes períodos de desenvolvimento. Entre nós a década de 60 é pobre na perspectiva internacional de uma "investigação de programa", prosseguido com objectivos programáticos por grupos científicos com alguma massa crítica e de forma sustentada. Nesta década, aliás como nas anteriores, a investigação era em geral esporádica, individual e destinada à progressão académica. Na década de 70 , graças à criação dos Centros de Estudos de Energia Nuclear em Lisboa, Coimbra e Porto, e aos esforços do Instituto de Alta Cultura (IAC), há um fomento significativo de doutoramentos no estrangeiro nas áreas de ciências exactas e naturais. Muitos desses doutores vão criar grupos de investigação e são o motor da investigação científica que o IAC e a agência de investigação universitária que se lhe seguiu, o Instituto Nacional de Investigação Científica (INIC), vieram a organizar em "centros de investigação" universitários nos finais da década de 70. É o fruto desta política que hoje se pode avaliar em termos da quantidade e, com maior importância, da qualidade da ciência produzida em Portugal. Os frutos da política da década de 90, após a extinção do INIC, e da injecção de fundos estruturais da União Europeia, só poderão ser avaliados no final desta década.

Diversos indicadores podem ser utilizados para avaliar a competividade de Portugal no seio da União Europeia. As Tabelas III, IV e V reúnem alguns índices relevantes para este efeito. Alguns desses indicadores ilustram o baixo investimento que Portugal faz em investigação e desenvolvimento experimental e tecnológico (ID), muito inferior ao de países europeus que têm uma população activa da nossa dimensão ou um pouco inferior (Tabela III). Não tem expressão a fracção de ID realizada no sector industrial nacional, como se verifica pelo reduzidíssimo pedido de patentes portuguesas, quer no país quer para o exterior, mesmo em função das despesas em ID no sector empresarial. Aliás o baixo investimento que Portugal tem em ID resulta muito mais da sua carência no sector industrial do que no Estado. Mas isto só reflecte a ausência de necessidade em ID realizado no país, por parte da indústria instalada em Portugal.

Não obstante os esforços que os países da União Europeia estão a operar no desenvolvimento tecnológlco, a Tabela IV revela bem a falta de competitividade da Europa em relação aos Estados Unidos e, muito especialmente, em relação ao Japão. Falta de competitividade que não se verifica na produção científica, pois aí é responsável por $1 / 3$ do conhecimento científico que se produz no mundo. Os 
indicadores da Tabela IV mostram ainda que a globalização da ciência não é fruto da produção científica em diversas partes do mundo; três grandes blocos concentram quase $80 \%$ dessa produção. A globalização deriva da difusão do conhecimento por meio de canais e redes semelhantes às que difundem os capitais a nível mundial. O conhecimento científico acaba por ficar atraído naqueles locais, regiões e países onde pode ser utilizado de forma mais eficiente para valor produtivo. Por isso tem crescido o número de pedidos de patentes por países ricos no estrangeiro. Esta taxa de "patentes no exterior" versus "patentes no interior" representa a difusão da inovação; por exemplo, esta taxa de difusão de inovação para os Países Nórdicos cresceu de 3,7 em 1987 para 11,6\% em 19936. Outros indicadores apontam ainda neste sentido de globalização, como o nível de investimento estrangeiro em ID; nos Estados Unidos este investimento era pouco mais de $2 \%$ em 1980, $4 \%$ em 1987 e $8,5 \%$ em 1993. Destes investimentos 76,4\% provêm da Europa e 9,9\% do Japão. O número de alianças estratégicas internacionais, de carácter tecnológico, tem vindo a crescer, mormente nas tecnologias de informação e em biotecnologia.

Analisada a problemática da investigação industrial, debruçamo-nos agora na investigação pura e aplicada a nível de universidades e academias e institutos de pesquisa. A Tabela $\mathrm{V}$ apresenta a produtividade científica nacional nas áreas de Matemática, Física e Química, medida em artigos publicados em revistas registadas no Science Citation Index (SCI), e atribuídos no todo ou em parte a grupos de investigação portugueses (artigos em contagem fraccionada). Trata-se de um indicador quantitativo. As citações dos artigos científicos já constituem um indicador de qualidade. Uma citação demonstra, em sentido amplo, que um dado artigo é relevante para a investigação de outros autores, patenteia o crédito que the conferem alguns cientistas e, ao mesmo tempo, chama a atenção das comunidades científicas para certos resultados, teorias, métodos, técnicas, conceitos, ideias, etc.. Contudo, na perspectiva de uma satisfatória avaliação da qualidade, não são indicadores como o número de "artigos publicados" ou até o número total de "citações" que devem ser utilizados. É o número de "citações por artigo". Edward comparou estes três tipos de indicadores nos 49 melhores químicos orgânicos do mundo, para a sua produção científica no período de 1965 a 1978; só o último destes indicadores revela a excelência de Robert Woodward, unanimente considerado um génio da química, com 74 citações por artigo; o segundo melhor tem 35 e $049 .^{\circ}$ químico orgânico tem 6 citações por artigo ${ }^{7}$. Com base nos estudos bibliométricos para os Centros do INIC no período de 1975-85, apresentamos na Tabela V diversos indicadores bibliométricos para a investigação científica universitária ${ }^{8}$. Um valor médio de 4,6 citações/artigo é excelente para a ciência portuguesa. O número de citações varia de área para área em função do número de investigadores e da maior ou menor dificuldade em produzir novos conhecimentos. Quando este indicador é normalizado ao número de publicações, obtém-se igual índice para a Física 
e um pouco inferior para a Matemática. Mas globalmente a qualidade da ciência produzida em Portugal foi bastante boa no período em estudo.

\section{PERSPECTIVAS FUTURAS}

Muitos dos problemas estruturais da Europa resultam do facto dos seus países - governos e populações - não se terem apercebido suficientemente de que para distribuir prosperidade e riqueza há primeiro que produzir valor acrescentado em bens e serviços. Toda a economia tem limites no volume de bens públicos que podem ser distribuídos de forma gratuita ou subsidiada. E hoje, mais do que ontem, a riqueza e o interesse social assentam numa eficiente produção de bens $\mathrm{e}$ serviços de alta e uniforme qualidade e alto grau de inovação, que têm de ser colocados no mercado de forma rápida e a baixos preços.

Nos Estados Unidos e em muitos países europeus os jovens continuam a privilegiar o direito, a sociologia, a psicologia ou as artes, em detrimento das engenharias e das ciências. Em contraste, na Coreia do Sul, entre 1976 e 1988, o número de engenheiros cresceu 7 vezes e hoje é superior ao da França. Apesar de as sociedades pós-modernas de hoje, e muito mais no futuro, estarem moldadas por factores científicos e tecnológicos, verifica-se uma acentuada iliteracia nas sociedades ocidentais sobre o contributo destes domínios para a economia e a qualidade de vida.

Nesta contextura a Europa sente-se ameaçada na sua competitividade, mesmo na perspectiva de um incremento no papel da componente de produção de serviços no crescimento económico. Neste campo encontram-se desfavorecidos os países do Sudeste Asiático e mais favorecido, a nível europeu, a Grã-Bretanha. Mas o futuro só se mostra risonho para países, regiões e empresas que consigam gerir equilibradamente um compósito de recursos humanos muito qualificados em tecnologia avançada, com capacidade de resposta rápida e sustentada à mudança permanente.

Relatórios recentes produzidos a nível da União Europeia, Quality and Relevance. The Challenge for European Education ${ }^{9}$ e Moving Towards a Learning Society ${ }^{10}$ realçam que é o sector industrial o que mais tem mudado na Europa e melhor se tem adaptado à mudança, graças a transformações tecnológicas, de mercado, sociais e demográficas, e à necessidade vital de competir. No extremo oposto encontramos as instituições de ensino, onde as mudanças são mais lentas e a resistência à própria mudança é mais elevada, por falta de padrões de desempenho, por ausência de competitividade, por interesses estabelecidos, por carência de motivação. Daí que os relatórios apontem para uma parceria educação/indústria no renascimento da educação europeia, mediante uma renovação sistémica em moldes mais articulados com os sectores mais relevantes na eco- 
nomia. Aliás a própria indústria tem vindo a adquirir uma maior componente social; o seu objectivo já não é o lucro tout court, mas surgem preocupações ambientais, de segurança e éticas.

A sociedade já não requer tanto especialistas como profissionais. Por outras palavras, as instituições de ensino, e nomeadamente as universidades, carecem de preparar, de novo, generalistas com competência técnica, social e organizacional; com flexibilidade mental, espírito de empreendimento e capacidade de simultaneamente liderar ou se integrar numa equipa de trabalho. A sociedade necessita de um largo espectro deste tipo de graduados, mas com diferentes compósitos de conhecimentos básicos e competências.

Uma das soluções apontadas para a resolução dos problemas que afligem a Europa parece ser, assim, a criação de uma forte educação básica, sob o lema das "três culturas": matemática, ciências e tecnologia; humanidades; domínios económicas e sociais. Mas o próprio sistema educativo carece de mudar na busca da "qualidade total". Esta mudança não virá de dentro. Carece de ser impulsionada pelos sectores com maior intervenção na economia, muito especialmente a indústria. Para que o sistema educativo actue segundo conceitos de produtividade e eficiência. Relevância dos "curricula" escolares em conhecimentos básicos e estruturantes, padrões de qualidade, adequada organização do ensino/aprendizagem, gestão académica e financeira eficiente, qualidade do corpo docente, apendizagem eficaz dos estudantes e adequadas metodologias de formação, laboratórios actualizados e bem equipados; demais infra-estruturas condignas.

Eis a visão e os remédios que decorrem de uma análise científica reducionista. Mas há necessidade de um outro tipo de reflexão de índole mais holística. Trata-se essencialmente de tomar consciência da degenerescência cultural que se está a avolumar no mundo ocidental, porque toda a cultura pressupõe uma firme concepção do homem e da sociedade. No passado, os factores de coesão da sociedade que moldaram as culturas da humanidade foram factores de simplicidade: os mitos, as religióes, que conferiram um sentido à existência humana. A época das "luzes" e o desenvolvimento científico e tecnológico pareciam apontar para uma nova dominante cultural: a ciência. Mas a ciência é demasiado complexa e mecânica para se constituir em laço de coesão social, em crença comum. Tais factores de coesão terão de provir de componentes mais espirituais, artísticas ou religiosas. As sociedades podem parecer funcionar bem quando se examinam somente à luz dos indicadores de progresso económico, mas podem estar a perder a sua alma e os seus factores de coesão quando examinadas na perspectiva da vida política ou da vertente espiritual ${ }^{11}$. Possuir uma cultura é saber situar-se em relação ao universo e aos outros homens, em relação ao passado e em relação ao futuro, em relação ao prazer e ao sofrimento, em relação à vida e à morte. O progresso não é uma forma de cultura, porque não pode ser desligado do conceito que a sociedade tem a respeito do seu próprio futuro. 


\section{NOTAS}

1 "Leonardo da Vinci já deve estar de novo por ai", F. Carvalho Rodrigues, em Política Cientifica e Tecnológica para os Anos 90, JNICT, 1991, p. 256.

2 Quality and Relevance. The Challenge to European Education, IRDAC (União Europeia), 1994 , p. 7 .

3 Inventer Demain, Comissão Europeia, 1996, p. 16.

4 The Economist, 29 de Março, 1997.

5 H. McRae, The World in 2020, Harper Collins Publ., 1994, p. 78.

6 Academy Update, New York Academy of Sciences, Abril/Maio/Junho 1997, p. 5.

7 "Be cited or perish", J. T. Edward, CHEMTECH, 22 (1992), 534.

8 "Resultados preliminares da avaliação bibliométrica de alguns Centros do INIC", J. M. G. Caraça, A. Romão Dias, G. Lopes da Silva e A. V. Xavier, Revista CTS, n. ${ }^{\circ} 3$ (1987), 4.

9 Quality and Relevance. The Challenge for European Education, IRDAC (Comité consultivo para a investigação industrial e o desenvolvimento), União Europeia, 1994.

10 P. Cochinaux e P. de Woot, Moving Towards a Learning Society, a CRE-ERT forum report on European Education, Universidade de Lovaina, 1995.

1 P. Thuillier, La Grande Implosion. Rapport sur l'effrondement de l'Occident 1999-2002, Fayard, 1997. 
Tabela I

TERCEIRO ESTUDO INTERNACIONAL SOBRE MATEMÁTICA E CIÊNCIAS

\begin{tabular}{|c|c|c|c|}
\hline \multicolumn{4}{|c|}{$\begin{array}{l}\text { Classificações médias obtidas por adolescentes de } 13 \text { anos de idade } \\
\text { (valor médio }=\mathbf{5 0 0} \text { ) }\end{array}$} \\
\hline \multicolumn{2}{|c|}{ Matemática } & \multicolumn{2}{|c|}{ Ciências } \\
\hline Singapura & 643 & Singapura & 607 \\
\hline Corẹia do Sul & 607 & República Checa & 574 \\
\hline Japã் & 605 & Japão & 571 \\
\hline Hong Kong & 588 & Coreia do Sul & 565 \\
\hline Bélgica (Flandres) & 565 & Bulgária & 565 \\
\hline República Checa & 564 & Holanda & 560 \\
\hline Eslováquia & 547 & Eslovénia & 560 \\
\hline Suíça & 545 & Áustria & 558 \\
\hline Holanda & 541 & Hungria & 554 \\
\hline Eslovénia & 541 & Inglaterra & 552 \\
\hline Bulgária & 540 & Bélgica (Flandres) & 550 \\
\hline Áustria & 539 & Austrália & 545 \\
\hline França & 538 & Eslováquia & 544 \\
\hline Hungria & 537 & Rússia & 538 \\
\hline Rússia & 535 & Irlanda & 538 \\
\hline Austrália & 530 & Suécia & 535 \\
\hline Irlanda & 527 & EUA & 534 \\
\hline Canadá & 527 & Canadá & 531 \\
\hline Bélgica (Walónia) & 526 & Alemanha & 531 \\
\hline Tailândia & 522 & Noruega & 527 \\
\hline Israel & 522 & Tailândia & 525 \\
\hline Suécia & 519 & Nova Zelândia & 525 \\
\hline Alemanha & 509 & Israel & 524 \\
\hline Nova Zelândia & 508 & Hong Kong & 522 \\
\hline Inglaterra & 506 & Suíça & 522 \\
\hline Noruega & 503 & Escócia & 517 \\
\hline Dinamarca & 502 & Espanha & 517 \\
\hline EUA & 500 & França & 498 \\
\hline Escócia & 498 & Grécia & 497 \\
\hline Letónia & 493 & Islândia & 494 \\
\hline Espanha & 487 & Roménia & 486 \\
\hline Islândia & 487 & Letónia & 485 \\
\hline Grécia & 484 & Portugal & 480 \\
\hline Roménia & 482 & Dinamarca & 478 \\
\hline Lituânia & 477 & Lituânia & 476 \\
\hline Chipre & 474 & Bélgica (Walónia) & 471 \\
\hline Portugal & 454 & Irão & 470 \\
\hline Irão & 428 & Chipre & 463 \\
\hline Kuwait & 392 & Kuwait & 430 \\
\hline Colômbia & 385 & Colômbia & 411 \\
\hline África do Sul & 354 & África do Sul & 326 \\
\hline
\end{tabular}

Fonte: The Economist, 29 de Março, 1997. 


\section{Tabela II}

MÉDIA DA CLASSIFICAÇÃO DE PROVAS ESPECÍFICAS DE QUÍMICA EM FUNÇÃO DOS LOCAIS ONDE FORAM REALIZADAS AS PROVAS NO ANO DE 1993 E 1994

Classificações médias obtidas por adolescentes de 13 anos de idade
(valor médio $=500$ )

Nota: À classificação média em cada localidade foi atribuído arbritariamente o n." 500 , para maior facilidade de comparação com a tabela anterior. 
Tabela III

INVESTIGAÇÃO E DESENVOLVIMENTO (ID)

A NÍVEL ESTATAL E DA INDÚSTRIA:

\begin{tabular}{|c|c|c|c|c|}
\hline População activa/milhões & $\begin{array}{c}\text { Portugal } \\
4,522\end{array}$ & $\begin{array}{c}\text { Bélgica } \\
4,217\end{array}$ & $\begin{array}{c}\text { Dinamarca } \\
2,799\end{array}$ & $\begin{array}{c}\text { Noruega } \\
2,171\end{array}$ \\
\hline Despesas de ID em \% PIB & $0,42 \%^{\text {b) }}$ & $1,58 \%$ & $1,37 \%$ & $1,83 \%$ \\
\hline $\begin{array}{c}\text { Despesas de ID financiadas } \\
\text { pelo Estado, \% PIB }\end{array}$ & $0,31 \%{ }^{\text {b) }}$ & $0,45 \%$ & $0,57 \%$ & $0,66 \%$ \\
\hline $\begin{array}{c}\text { Despesas de ID financiadas } \\
\text { pela Indústria, fração do total }\end{array}$ & $26,8 \%{ }^{\text {b) }}$ & $69,3 \%$ & $49,2 \%$ & $51,0 \%$ \\
\hline $\begin{array}{c}\text { Pedido de patentes Nacionais } \\
\text { no País } \\
\text { no Estrangeiro }\end{array}$ & 77 & 975 & 958 & 903 \\
\hline $\begin{array}{c}\text { Pedido de patentes por despesa } \\
\text { (milhões de dólares) } \\
\text { no sector empresarial }\end{array}$ & 124 & 5167 & 4899 & 2544 \\
\hline $\begin{array}{c}\text { Taxa de cobertura do Balanço } \\
\text { de Pagamento Tecnológico }\end{array}$ & 0,45 & 1,14 & 0,37 & 0,11 \\
\hline
\end{tabular}

“' Dados de 1987 excepto em ${ }^{\text {b) }}$ (1986) e el (1985); dados coligidos por A. Barroso na obra da nota 1.

Tabela IV

PRODUTIVIDADE DE ARTIGOS CIENTÍFICOS E PATENTES EM 1993

\begin{tabular}{|l|c|c|c|}
\hline \multirow{2}{*}{} & \multirow{2}{*}{ Artigos } & Reg. Estados Unidos & Reg. União Europeia \\
\cline { 3 - 4 } & & & \\
\hline União Europeia & $32 \%$ & $18,6 \%$ & $45,4 \%$ \\
\hline Estados Unidos & $38 \%$ & $48,7 \%$ & $27,3 \%$ \\
\hline Japão & $8 \%$ & $25 \%$ & $20,9 \%$ \\
\hline
\end{tabular}




\section{Tabela V \\ PRODUTIVIDADE CIENTÍFICA PORTUGUESA PERÍODO 1975-1985}

\begin{tabular}{|c|c|c|c|}
\hline Produtividade & Matemática & Física & Química \\
$\begin{array}{c}\text { Produção de artigos com } \\
\text { contagem fraccionada } a \text { ) }\end{array}$ & 146,4 & 548,4 & 499 \\
\hline $\begin{array}{c}\text { N." artigo } \\
\text { SCl/ano/autor } b \text { ) }\end{array}$ & 0,26 & 0,70 & 0,38 \\
\hline N." citações/n." artigo/SCI $b$ ) & 1,22 & 5,6 & 4,65 \\
\hline $\begin{array}{c}\text { Citações/artigo SCI } \\
\text { normalizado }\end{array}$ & 3,75 & 4,6 & 4,65 \\
\hline
\end{tabular}

Fonte: C. Marciano da Silva "Ciência em Portugal”, Imprensa Nacional, Europália, 91, p. 48.

"Resultados Preliminares da Avaliação Bibliométrica de Alguns Centros do INIC", J. M. G. Caraça, A. Romão Dias, G. Lopes da Silva e A. V. Xavier, Revista CTS, $\mathrm{n}^{\circ} 3$.

a) Dados coligidos por C. Marciano da Silva, "Ciência em Portugal", Imprensa Nacional, Europália, 91, p. 48.

b) "Resultados Preliminares da Avaliação Bibliométrica de Alguns Centros do INIC”, J. M. G. Caraça, A. Romão Dias, G. Lopes da Silva e A. V. Xavier, Revista CTS, n. ${ }^{\circ} 3$. 
Figura I

GASTOS DO ESTADO POR ALUNO* (,\$’00 PPP 1993)

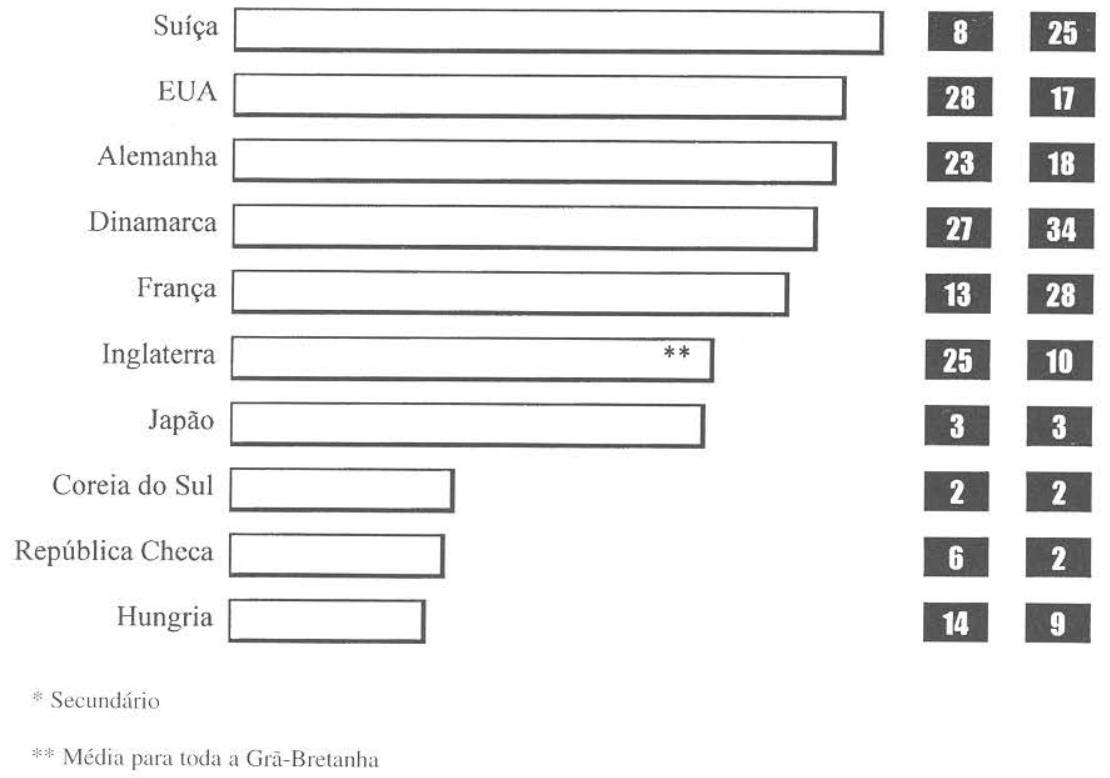

Fonte: cf. nota 4.

Figura II

MATEMÁTICA: HORAS DE ENSINO POR ANO - PUNTUAÇÃO

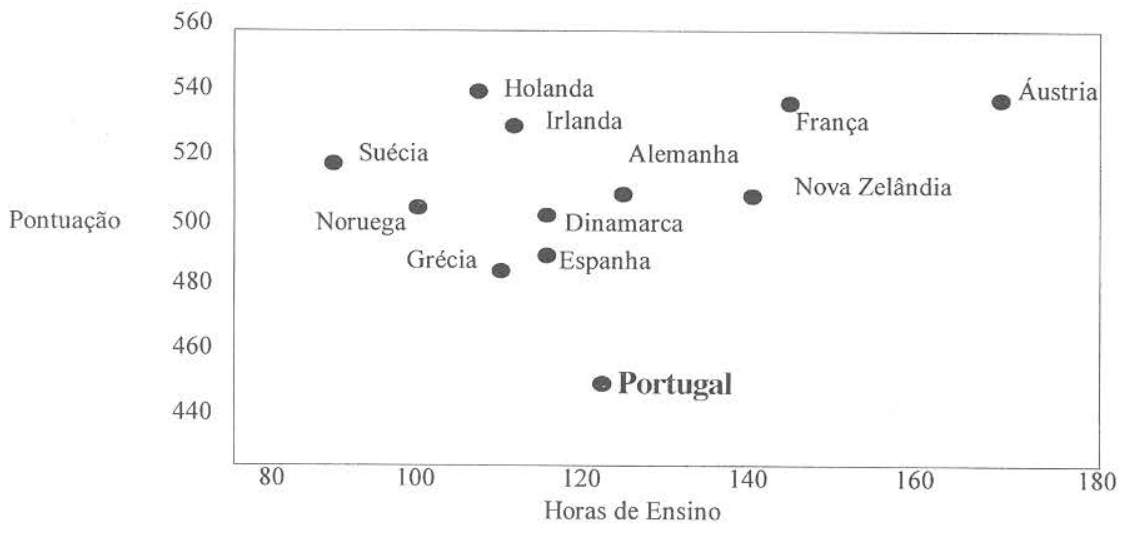

